\title{
SIMULAÇÃO DO APROVEITAMENTO DA ENERGIA EÓLICA PARA IRRIGAÇÃO NO DISTRITO DE IRRIGADO BAIXO-ACARAÚ - CE ${ }^{1}$
}

\author{
Erialdo de Oliveira Feitosa ${ }^{2}$, Daniel Albiero ${ }^{3}$, Aline Castro Praciano ${ }^{4}$, Deivielison Ximenes \\ Siqueira Macedo ${ }^{5}$, Carlos Alessandro Chioderoli ${ }^{6}$
}

\footnotetext{
${ }^{1}$ Aceito para publicação em $2^{\circ}$ trimestre de 2014

${ }^{2}$ Mestre em Engenharia Agrícola, Universidade Federal do Ceará - UFC;

${ }^{3}$ Doutor em Engenharia Agrícola - Unicamp, Docente na Universidade Federal do Ceará - UFC;

${ }^{4}$ Acadêmica do curso Superior de Agronomia, Universidade Federal Do Ceará - UFC;

${ }^{5}$ Mestre em Engenharia Agrícola, Universidade Federal do Ceará - UFC;

${ }^{6}$ Doutor em Ciências do Solo, UNESP Campus de Jaboticabal;
}

\section{Resumo}

A geração de energia elétrica proveniente de sistemas eólicos surge como uma alternativa de grande potencial para a região Nordeste do Brasil, podendo promover o desenvolvimento econômico e social da região. Os sistemas de irrigação utilizados nos perímetros irrigados demandam quantidades significativas de energia, o que aumenta consideravelmente o custo de produção final. O trabalho objetivou a simulação da geração de energia elétrica provinda da fonte eólica como alternativa energética para o perímetro irrigado do Baixo-Acaraú, CE. Para tal foi utilizado o software EOLUSOFT - Versão Beta 1.0 NUTEMA-PUCRS desenvolvido na PUC do Rio Grande do Sul, pelo Núcleo Tecnológico de Energia e Meio Ambiente, e no bombeamento de água foi considerada uma bomba d água de $5 \mathrm{cv}$ com capacidade para bombear 10.800 l/h. Como resultado da simulação o sistema eólico apresentou-se possível de atender as necessidades de alimentação elétrica rural no perímetro irrigado com as condições de velocidade de vento analisados para o local, sendo capaz de fornecer o abastecimento de água para a irrigação.

Palavras-chave: Energia renovável, geração de energia, potencial eólico. 


\title{
SIMULATION OF UTILIZATION THE WIND ENERGY FROM IRRIGATION IN IRRIGATED DISTRICT BAIXO-ACARÁU - CE
}

\begin{abstract}
The generation of electric energy from wind systems arises as an alternative of great potential for the Northeast region of Brazil, which will promote the economic and social development of the region. The irrigation systems utilized in irrigated areas demand significant quantities electricity, which considerably increases the cost of final production. The study aimed the simulation of generation of electric energy from wind source how energy alternative for Irrigated Baixo-Acaraú-CE. For this we used the software EOLUSOFT - Version 1.0 Beta NUTEMA-PUCRS developed at PUC in Rio Grande do Sul, the Technological Center of Energy and Environment. Pumping of water was considered a bomb d $5 \mathrm{hp}$ water pump with a capacity of $10.8001 / \mathrm{h}$. How result of the wind system simulation presented it possible to meet the needs of rural power supply in irrigated conditions with wind speed analyzed for the site, being able to provide water for irrigation.
\end{abstract}

Keywords: Renewable energy, power generation, wind potential.

\section{Introdução}

A energia elétrica é um insumo importantíssimo para o desenvolvimento das civilizações modernas, estando presente em quase todas as atividades dos processos produtivos (MEDEIROS et al., 2003). Dentre os setores consumidores de energia, a agricultura irrigada desponta como altamente dependente para aumentar a produção e conseguir suprir as necessidades do mercado, que é cada vez mais exigente e competitivo.

Com advento da agricultura irrigada veio o aumento produtivo das culturas, mas no Brasil esse modelo de agricultura ocupa apenas $10 \%$ da área total cultivada no país, e é responsável por aproximadamente $30 \%$ do valor bruto da produção agrícola (LARA, 2010). Porém, com a implantação dos projetos públicos de irrigação com suas infraestruturas de captação e adução, reservatórios, estações de bombeamento, canais, adutoras, faz-se necessário a utilização da energia elétrica, por consequência, representa um forte componente nos custos totais que podem chegar a $35 \%$ do custo da produção, reduzindo a margem de lucro do produtor (ANA, 2004).

Revista Brasileira de Energias Renováveis, v. 3, p. 65-79, 2014 
De acordo com Turco et al. (2009), a irrigação é responsável por grande parte do consumo de energia no perímetro irrigado, e este pode ser ainda maior se o produtor rural não adotar um método de controle da irrigação. A justificativa do irrigante para o consumo de água em excesso está relacionada, em geral, à preocupação de que a cultura não sofra estresse hídrico, o que poderia comprometer a produção. $\mathrm{O}$ descontrole da irrigação gera um aumento do custo de produção pelo desperdício dos recursos energia e água.

Como exemplo dessa iminente preocupação do setor rural, no Perímetro Irrigado Baixo-Acaraú, do Departamento Nacional de Obras Contra as Secas - DNOCS, localizado na região Norte do Estado do Ceará, onde se verifica que $30 \%$ dos custos de produção correspondem às despesas com energia elétrica suscitou a necessidade de geração de energia alternativa por meio da energia eólica que visa atender todo o consumo de energia elétrica dos produtores rurais. Portanto, torna-se fundamental inserir no processo produtivo fontes alternativas de energia que induzam a diminuição dos custos de energia elétrica na área rural em paralelo as ações de manejo racional da água. (ARAUJO et al., 2011).

Neste contexto o sistema de geração de energia elétrica por meio da energia dos ventos é fundamental para a região do Nordeste, pois apresenta elevado potencial do ponto de vista do aproveitamento dessa energia para promover um desenvolvimento sustentável, voltado ao atendimento da necessidade energética dos perímetros irrigados e para a sustentabilidade do crescimento econômico e social aliado a manutenção dos sistemas naturais água, solo, biodiversidade (SOBRAL, 2009).

Diante do exposto o presente trabalho objetivou realizar uma simulação da energia elétrica gerada por meio de aerogerador no perímetro irrigado Baixo-Acaraú - Ceará, Brasil, para a demanda energética dos sistemas de irrigação.

\section{Material e métodos}

O perímetro irrigado Baixo-Acaraú, está localizado na região Norte do Estado do Ceará, no trecho final da bacia do rio acaraú, abrangendo áreas dos municípios de Acaraú, Bela Cruz e Marco, entre as coordenadas geográficas $3^{\circ} 01^{\prime}$ de Latitude Sul e $40^{\circ} 01^{\prime}$ de Longitude Oeste, e Altitude de $20 \mathrm{~m}$. Tendo clima do tipo Aw Tropical Chuvoso, com temperatura média anual de $28,1^{\circ} \mathrm{C}$, precipitação média anual de $900 \mathrm{~mm}$, e evaporação média anual de $1600 \mathrm{~mm}$. (OLIVEIRA et al., 2012).

Segundo Oliveira et al. (2012) o distrito de irrigação do Baixo-Acaraú possui uma área irrigável total de 12.603 ha, porém, apenas 8.335 ha são cultivados, em que o restante da área 
ainda não foi ativada ou se destina à preservação, e sua demanda energética é atendida pela usina hidrelétrica de sobradinho. No entanto, a sua importância econômica está na diversidade de culturas produzidas no perímetro de alto valor agregado como abacaxi, banana, melão, melancia, e culturas de subsistências como feijão e milho, melhorando a qualidade de vida dos produtores que estão associados às atividades agrícolas desenvolvida no perímetro refletindo em altas produtividades e alta renda anual por produtor, (LACERDA e OLIVEIRA, 2007).

A velocidade média do vento é o principal parâmetro estatístico a ser utilizada para determinar a capacidade de produção de energia através do conhecimento do potencial eólico de uma região, então foram verificados os dados de vento dos últimos 11 anos, compreendendo o período de janeiro de 2000 a dezembro de 2010. Os mesmo foram obtidos por meio do Instituto Nacional de Meteorologia (INMET), são series de dados históricos medidos pelas estações meteorológicas convencionais, em que são digitalizados e armazenados em uma plataforma chamada BDMEP (Banco de Dados Meteorológicos para Ensino e Pesquisa).

O BDMEP é um banco de dados armazenados e mantidos pelo INMET, que tem a função de apoiar as atividades de ensino e pesquisa, o mesmo contém dados meteorológicos diários em forma digital, referentes a séries históricas da rede de estação do INMET relacionado às 191 estações meteorológicas convencionais.

As variáveis atmosféricas disponibilizada para consulta são velocidade e direção do vento, precipitação, temperatura do bulbo seco, temperatura do bulbo úmido, temperatura máxima e mínima, umidade relativa do ar, pressão atmosférica ao nível de cada estação, e insolação. Para ter acesso aos mesmos, tem-se que fazer um cadastro junto ao INMET, e especifica a finalidade de utilização dos dados, feito a sua solicitação, quando aprovado o usuário receberá um e-mail, com uma senha, e por meio do e-mail cadastrado e a senha recebida tem-se o acesso ao BDMEP, onde são disponibilizados dados horários, diários e mensais.

$\mathrm{Na}$ Figura 1, é apresentado o gráfico com médias anuais calculadas através das médias mensais obtidas no BDMEP coletado pela estação meteorológica de Acaraú, e realizado a extrapolação para a altura de $20 \mathrm{~m}$, compreendendo o período de 2000 a 2010 , em que as barras em azul representam a média anual calculada, onde a mesma foi $3,86 \mathrm{~m} \mathrm{~s}^{-1}$, e a linha vermelha o comportamento típico do vento durante cada ano analisado, bem como de forma geral qual ano teve maior velocidade do vento, consequentemente maior disponibilidade de energia. 


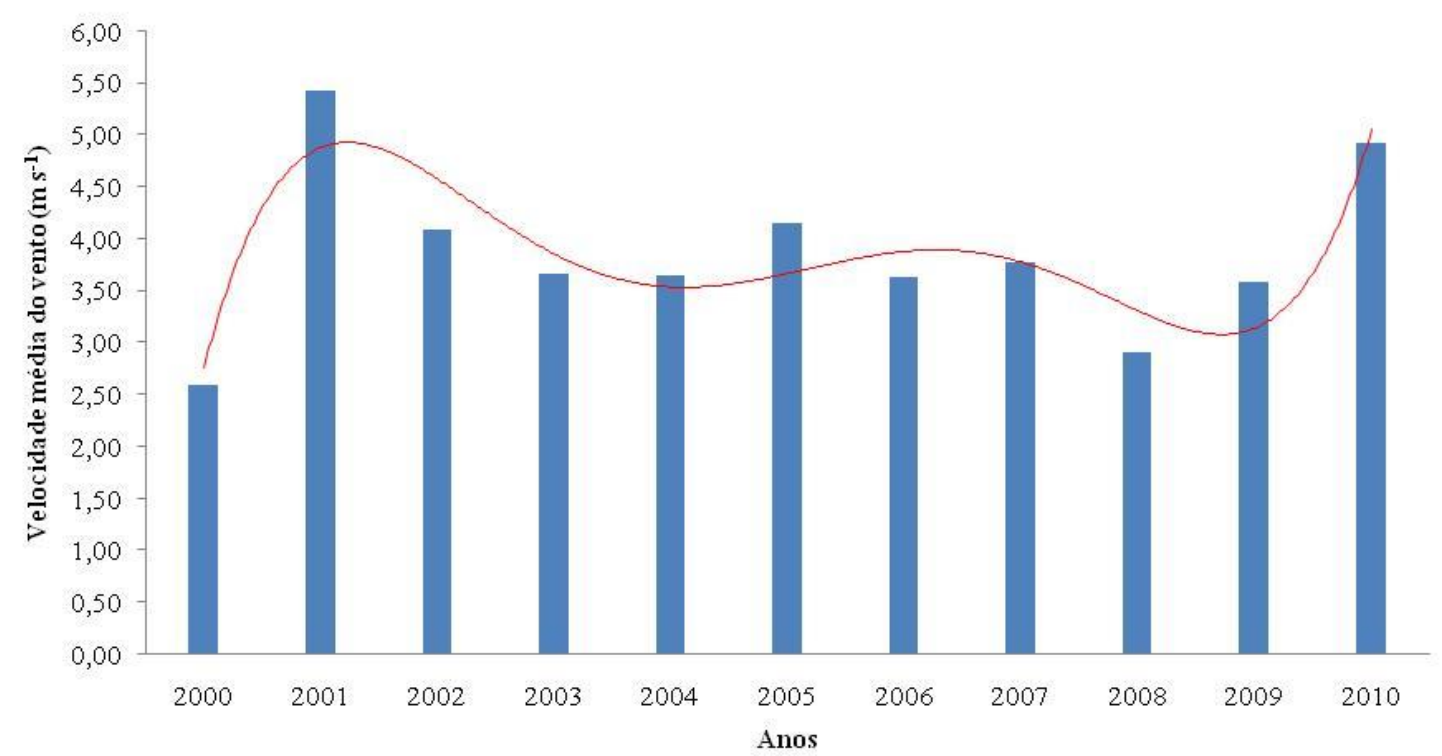

Figura 1: Velocidade média do vento no período de onze anos em Acaraú. Fonte: INMET, (2014).

O primeiro tratamento desses dados analisados foi á extrapolação da velocidade média do vento para a altura de $20 \mathrm{~m}$, em que a mesma corresponde à altura de instalação do aerogerador, foi necessário realizar essa extrapolação, uma vez que a estação meteorológica de Acaraú, e como a maioria dos postos de medição, possuem alturas de medição de velocidades de vento na ordem de $2 \mathrm{~m}$. Para realização dessa etapa foi utilizada a Lei de Hellmann que determina a velocidade de vento para um perfil vertical, e que é dado pela seguinte equação:

$\mathrm{V}_{\mathrm{h}_{2}}=\mathrm{V}_{\mathrm{h}_{1}} \times\left[\frac{\mathrm{h}_{2}}{\mathrm{~h}_{1}}\right]^{\alpha}$

Onde:

$\mathrm{h}_{1}=$ altura medida pela estação meteorológica;

$\mathrm{h}_{2}=$ altura de interesse;

$\mathrm{V}\left(\mathrm{h}_{1}\right)=$ velocidade média do vento na altura medida $\left(\mathrm{m} \mathrm{s}^{-1}\right)$;

$\mathrm{V}\left(\mathrm{h}_{2}\right)=$ velocidade medida do vento na altura de interesse $\left(\mathrm{m} \mathrm{s}^{-1}\right)$;

$\alpha=$ expoente de altitude de Hellmann (o valor de $\alpha$ depende da rugosidade do terreno e da estratificação térmica).

Na Tabela 1

Essa equação é usada para o cálculo da velocidade média horária na altura desejada, ou seja, a altura de funcionamento do aerogerador, em que existindo uma velocidade média 
conhecida a uma altura de referência, observando sempre o grau de rugosidade do terreno para a determinação do expoente apresentados na Tabela 1. Onde foi utilizado o alfa da classe 1 , devido as característica da área em estudo se aproximarem mais daquelas descritas por ela.

Tabela 1 - Classificação do grau de rugosidade do terreno na determinação do expoente

\begin{tabular}{|c|c|c|}
\hline Classe & $\alpha(\mathbf{m})$ & Tipo de área \\
\hline 0 & 0,0002 & Com água. Tais como mares e lagos. \\
\hline 1 & 0,0300 & $\begin{array}{l}\text { Aberta com poucos quebra-ventos, plana ou levemente ondulaoo0da, } \\
\text { podendo apresentar simples fazendas e árvores ou arbustos. }\end{array}$ \\
\hline 2 & 0,1000 & $\begin{array}{l}\text { Terrenos de fazendas com quebra-ventos afastados a mais de } 1000 \mathrm{~m} \\
\text { entre si, e algumas construções espalhadas; caracterizados por grandes } \\
\text { áreas abertas entre alguns quebra-ventos, com uma paisagem aberta; o } \\
\text { terreno pode ser plano ou ondulado. }\end{array}$ \\
\hline 4 & 0,4000 & $\begin{array}{l}\text { Áreas urbanas, florestas e terras de fazenda com muitos quebra-ventos } \\
\text { aglomerados, com separação média de poucas centenas de metros. }\end{array}$ \\
\hline
\end{tabular}
Fonte: CUSTÓDIO, 2009.

Na Figura 2, é apresentado o gráfico da velocidade média do vento referente a cada mês de todos os anos analisados, pois tornando se de fundamental importância conhecer a ocorrência da velocidade média do vento em cada mês para dimensionamento de demanda referente ao período de maior ou menor potencial para geração.

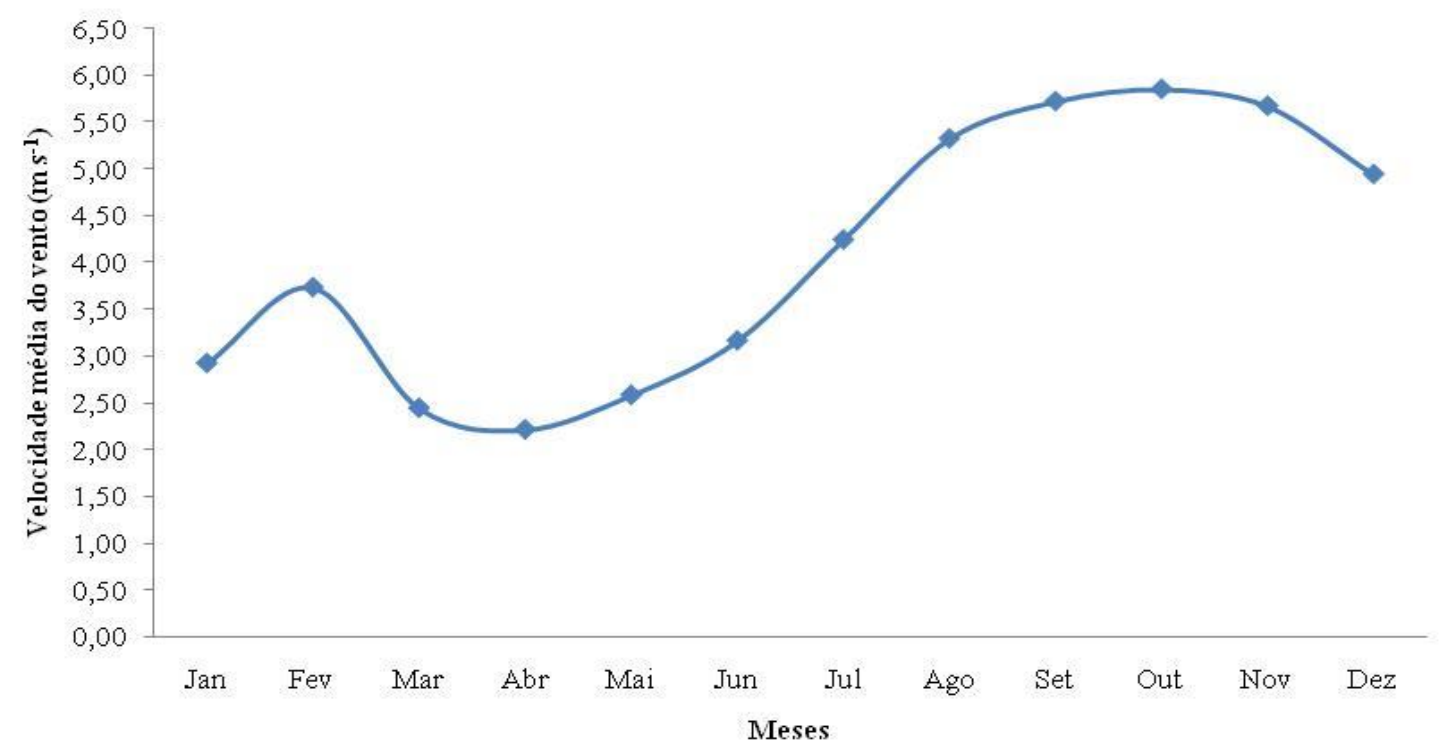

Figura 2: Variação da velocidade média do vento ao longo dos meses de 2000 a 2010. Fonte: INMET, (2013). 
Também foi calculada a função de distribuição de probabilidade de Weibull, amplamente difundida e testada nos estudos com energia eólica, onde foi usada a ferramenta GDER, em que essa ferramenta utiliza dados de velocidade média do vento e o desvio padrão para o calculo dos dois parâmetros da função de Weibull, o parâmetro de forma (k), e o de escala (c), em que utilizou-se a média anual de todos os anos avaliados, e o desvio padrão dessas dados. Pois devido à grande variabilidade da velocidade do vento em função do regime climático da região Nordeste de acordo com cada mês do ano, torna-se necessário conhecer a distribuição de probabilidade de freqüência da mesma.

Na etapa de simulação da geração de energia, foi realizada a análise da energia anual que pode ser gerado, em que foi analisado um aerogerador do modelo EXCEL com potência nominal de $10 \mathrm{~kW}$, diâmetro do rotor $7 \mathrm{~m}$, rotação nominal $350 \mathrm{rpm}$, e velocidade nominal de $13 \mathrm{~m} \mathrm{~s}^{-1}$, considerando a utilização de apenas uma turbina eólica para a geração de eletricidade para consumo no bombeamento de água visando a irrigação, e apenas um área de produtor rural que no perímetro Baixo-Acaraú representa em torno de 8 hectares. Para realização da mesma foi utilizado o software EOLUSOFT - Versão Beta 1.0 NUTEMA-PUCRS, que foi desenvolvido na PUC do Rio Grande do Sul, pelo Núcleo Tecnológico de Energia e Meio Ambiente através do Grupo de Energia Eólica da PUCRS.

O primeiro passo nesta etapa de simulação foi avaliar a velocidade média do vento durante o período medido e realizar a sua extrapolação para a altura de $20 \mathrm{~m}$, que seria a altura de funcionamento da turbina eólica para o local em estudo e simular um tipo de uso no caso irrigação, para verificar a possibilidade usando um único aerogerador de $10 \mathrm{~kW}$, e preenchendo as informações solicitadas pelo software sobre como a energia será consumida.

A próxima etapa foi preencher as informações para dimensionamento do sistema eólico informando o método utilizado para distribuição, no caso deste estudo a distribuição de Weibull, e outras informações visualizadas na tela do software mostradas nos resultados para gerar os dimensionamentos, com relação à demanda energética em função do bombeamento de água para irrigação com sistemas microaspersão e gotejamento foi considerado uma bomba d água de $5 \mathrm{cv}$ com vazão de $10.8001 \mathrm{~h}^{-1}$, e por fim em função das condições edafoclimaticas do local em estudo, foi calculado o consumo técnico de energia, obtendo o seguinte valor 2251,45 $\mathrm{kWh}$ durante um ciclo produtivo da cultura da banana no Perímetro Irrigado Baixo-Acaraú.

O esquema de funcionamento do sistema eólico de bombeamento é mostrado na Figura 3. O mesmo opera de forma direta, ou seja, o aerogerador tem a função de gerar energia, pois quando o vento entra em contato com a turbina, fazendo a mesma rotacionar ocorre à conversão 
da energia cinética do vento em energia mecânica, onde essa nova forma de energia é entregue ao gerador, o qual por meio dos processos eletromecânicos converte a para energia elétrica em corrente alternada (CA), uma vez que o aerogerador está conectado através de cabos a um controlador, no qual tem a função de estabilizar uma frequência e uma tensão de acionamento do conjunto motobomba, realizado essa fase o controlador entregue a essa energia para o inversor que apenas converte a mesma para uma corrente compatível com a carga, no caso especifico a motobomba, que uma vez acionado faz o processo de sucção da fonte hídrica e recalque para um reservatório elevado e finalmente a distribuição de água para o sistema de irrigação por gotejamento.

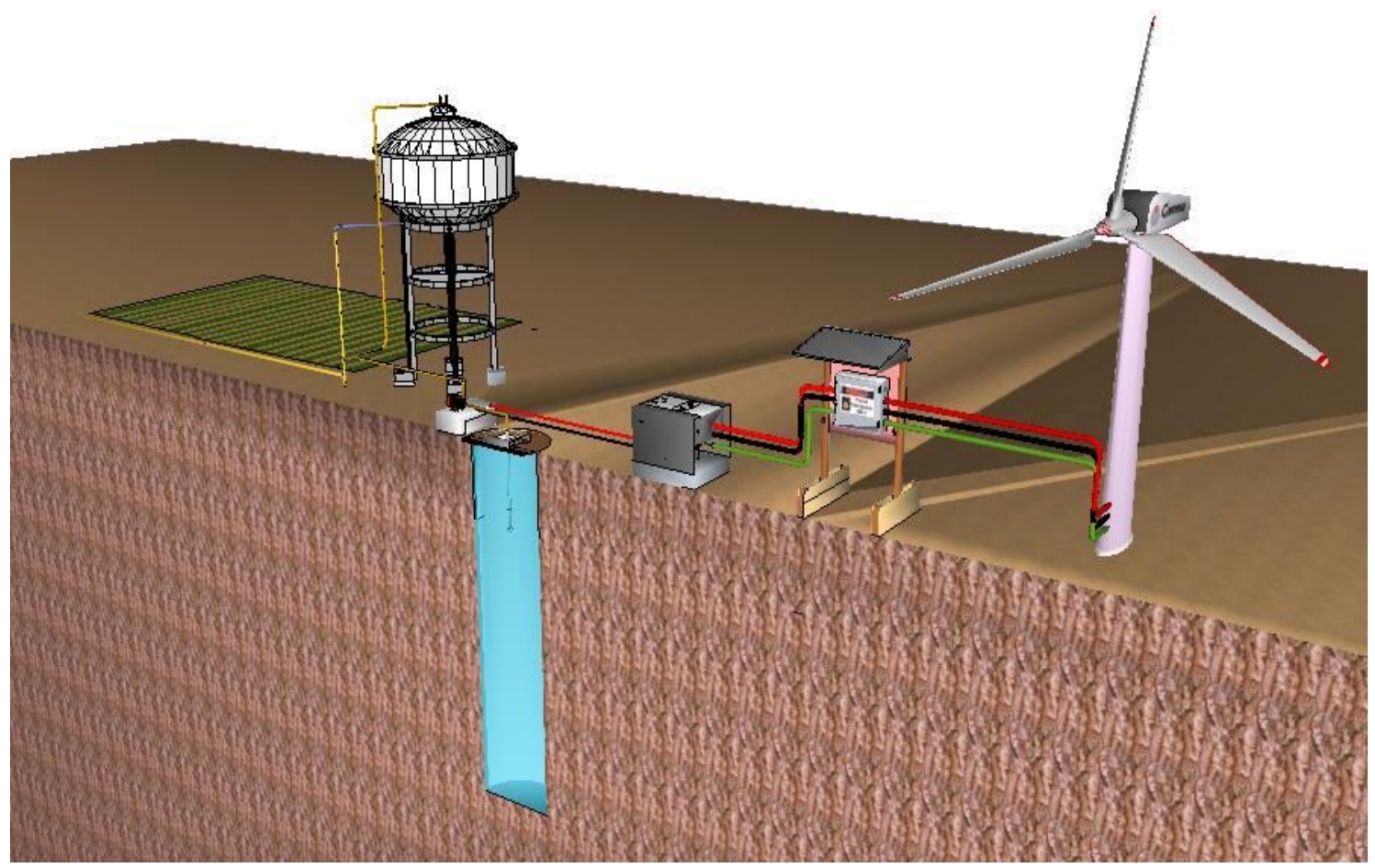

Figura 3: Esquema da planta do sistema acionado pelo aerogerador

Portanto a energia eólica captada pelo sistema de geração de energia elétrica é armazenada no reservatório elevado na forma de energia hidráulica potencial que acionará o sistema de irrigação por gotejamento gravitacional, de modo que se pode dispensar o uso de baterias.

\section{Resultados e discussão}

$\mathrm{Na}$ Figura 4, estão representados o histograma da velocidade do vento, com classes contendo velocidade dos ventos a cada $1 \mathrm{~m} \mathrm{~s}^{-1}$, e a curva da função continua de Weibull. Os 
retângulos em azul representam os dados, e a linha contínua é a curva de Weibull, onde esses valores apresentados na figura são coerentes com a velocidade média analisada durante a série histórica observada e que foi extrapolada para a altura de funcionamento da turbina eólica.

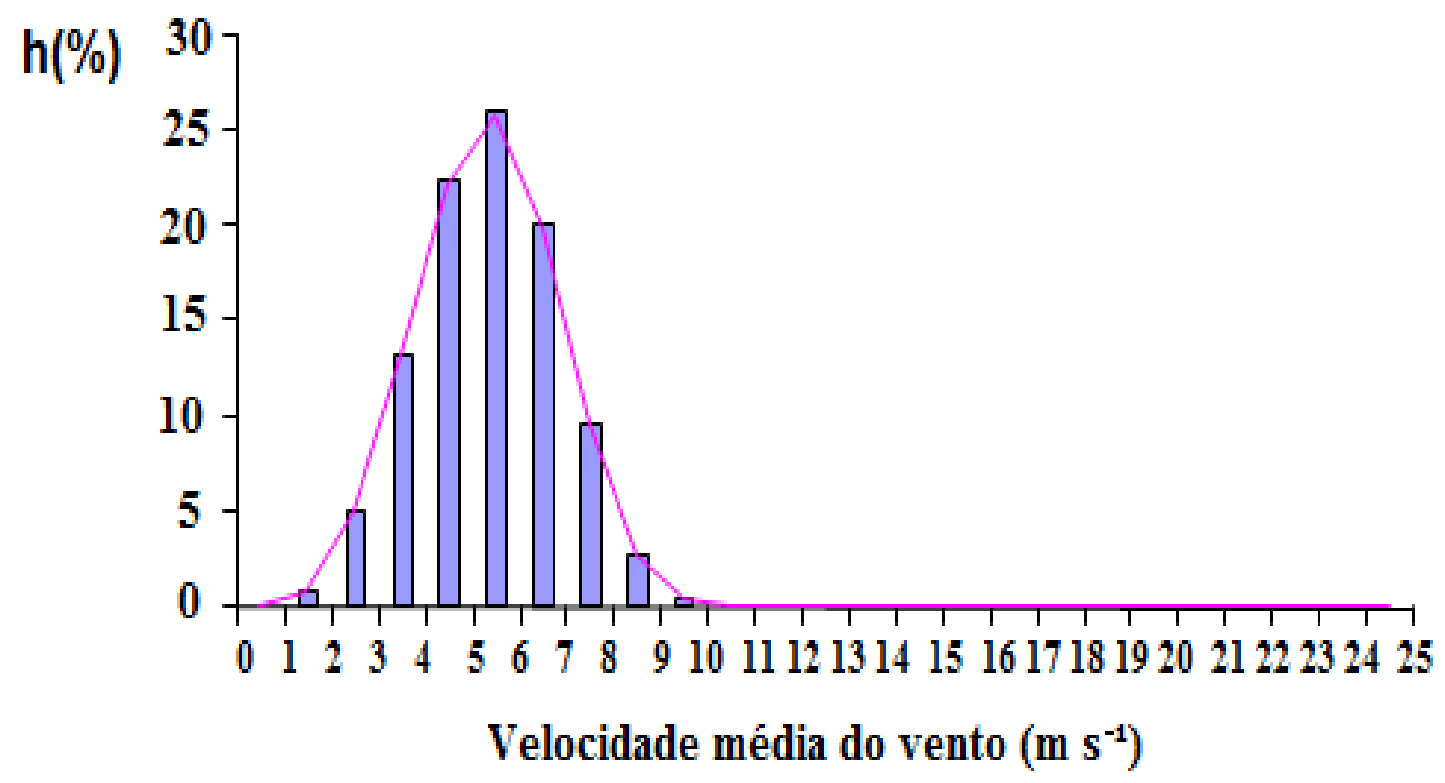

\section{Figura 4: Distribuição de Weibull e Histograma para a velocidade média do vento em Acaraú, CE.}

A distribuição das velocidades de vento no município de Acaraú - CE mostra que há probabilidade de $49 \%$ de ocorrência das velocidades verificadas no período analisado e que estão entre os intervalos superior a $4 \mathrm{~m} \mathrm{~s}^{-1}$ e inferior $6 \mathrm{~m} \mathrm{~s}^{-1}$ das velocidades medidas, e que pela distribuição das velocidades do local em estudo mostra a aderência da curva gerada pela distribuição de Weibull para a amostra de dados estudada.

O Brasil, diferentemente de muitos países desenvolvidos, possui um grande potencial eólico, principalmente no litoral do Nordeste (FIDELIS et al., 2005). Nessa região foram constatadas velocidades médias anuais entre 6 e $8,5 \mathrm{~m} / \mathrm{s}$ a 50 metros de altura, de direção predominantemente nordeste e pouca turbulência durante o ano, sendo os estados do Ceará e do Rio Grande do Norte os que possuem as áreas de maior potencial do país, além destes, foi verificado que no estado de Minas Gerais, mesmo a $100 \mathrm{~km}$ de distância do mar, possui um bom potencial eólico (FIDELIS et al., 2005).

$\mathrm{Na}$ Figura 5 é apresentada a curva de potência do aerogerador utilizado na simulação, considerando a utilização de apenas uma turbina eólica para a geração de eletricidade para consumo no bombeamento de água visando à irrigação no perímetro irrigado Baixo-Acaraú. Encontramos que com a velocidade média extrapolada para $20 \mathrm{~m}$ de altura correspondente a 
$5,10 \mathrm{~m} \mathrm{~s}^{-1}$, tem-se uma potência máxima de $1 \mathrm{~kW}$, sendo a velocidade que temos maior frequiência e probabilidade de ocorrência no local em estudo. E pode ser verificado também o seu aproveitamento máximo em relação aos ventos disponíveis na sua velocidade nominal a 13 $\mathrm{m} \mathrm{s}^{-1}$ atingindo uma potência de $10 \mathrm{~kW}$.

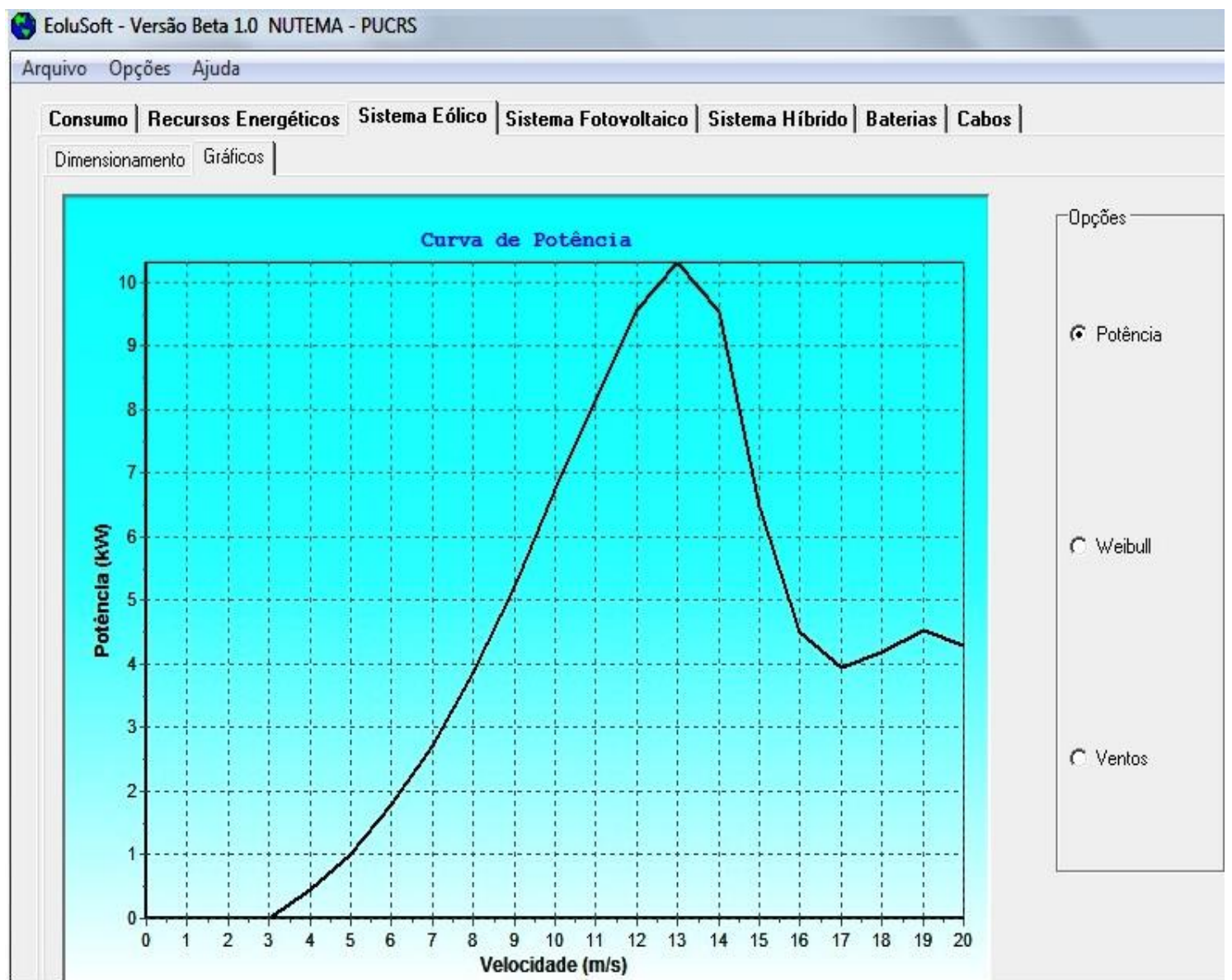

Figura 5: Curva de potencia do aerogerador utilizado na simulação da energia gerada.

Com relação à demanda energética a Figura 6 mostra o dimensionamento do consumo de energia a ser atendido pelo aerogerador utilizando uma bomba da água de $5 \mathrm{cv}$, com vazão de $10.8001 \mathrm{~h}^{-1}$ para a irrigação durante 4 horas por dia apresentando uma demanda de $7842 \mathrm{Wh}$ por dia. 


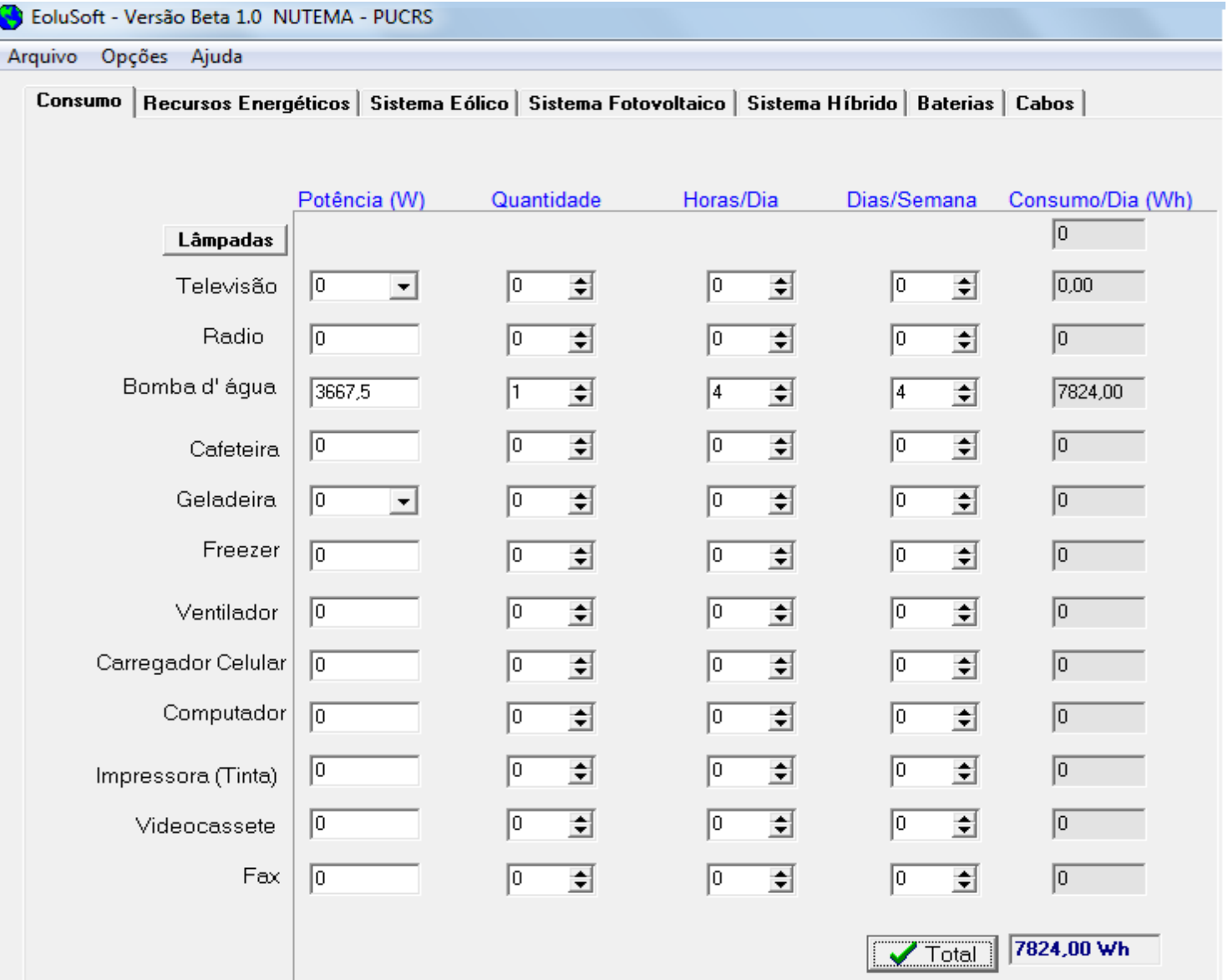

\section{Figura 6: Consumo energético pelo sistema de bombeamento de água para o perímetro irrigado Baixo-Acaraú, CE}

Segundo Nogueira, (2009) em seu estudo com fontes alternativas de energia chegouse a resultados que demonstraram viabilidade de equipamentos eólicos e solares fotovoltaicos para utilização na irrigação complementar nas culturas de goiabeira, figueira e videira.

Para a área de um produtor rural correspondente a 8 hectares no perímetro irrigado Baixo-Acaraú utilizando o sistema de referência adotado com este aerogerador é possível gerar anualmente 9.848,77 $\mathrm{kWh}$ com a velocidade média do vento de $5,10 \mathrm{~m} \mathrm{~s}^{-1}$, atendendo assim a demanda energética que é de 2.855,76 kWh Figura 7, podendo realizar uma compensação energética do excedente $6.993,01 \mathrm{kWh}$, perante as concessionárias de energia, conforme a lei 12.783 de 11 de janeiro de 2013 que dispõe sobre as concessões de geração, transmissão e distribuição de energia elétrica, e principalmente de acordo com a Resolução Normativa $n^{\circ} 482$ de 17 de abril de 2012, que estabelece as condições gerais para o acesso de microgeração e minigeração distribuídas aos sistemas de distribuição de energia elétrica e o sistema de compensação de energia elétrica. (ANEEL, 2014). 


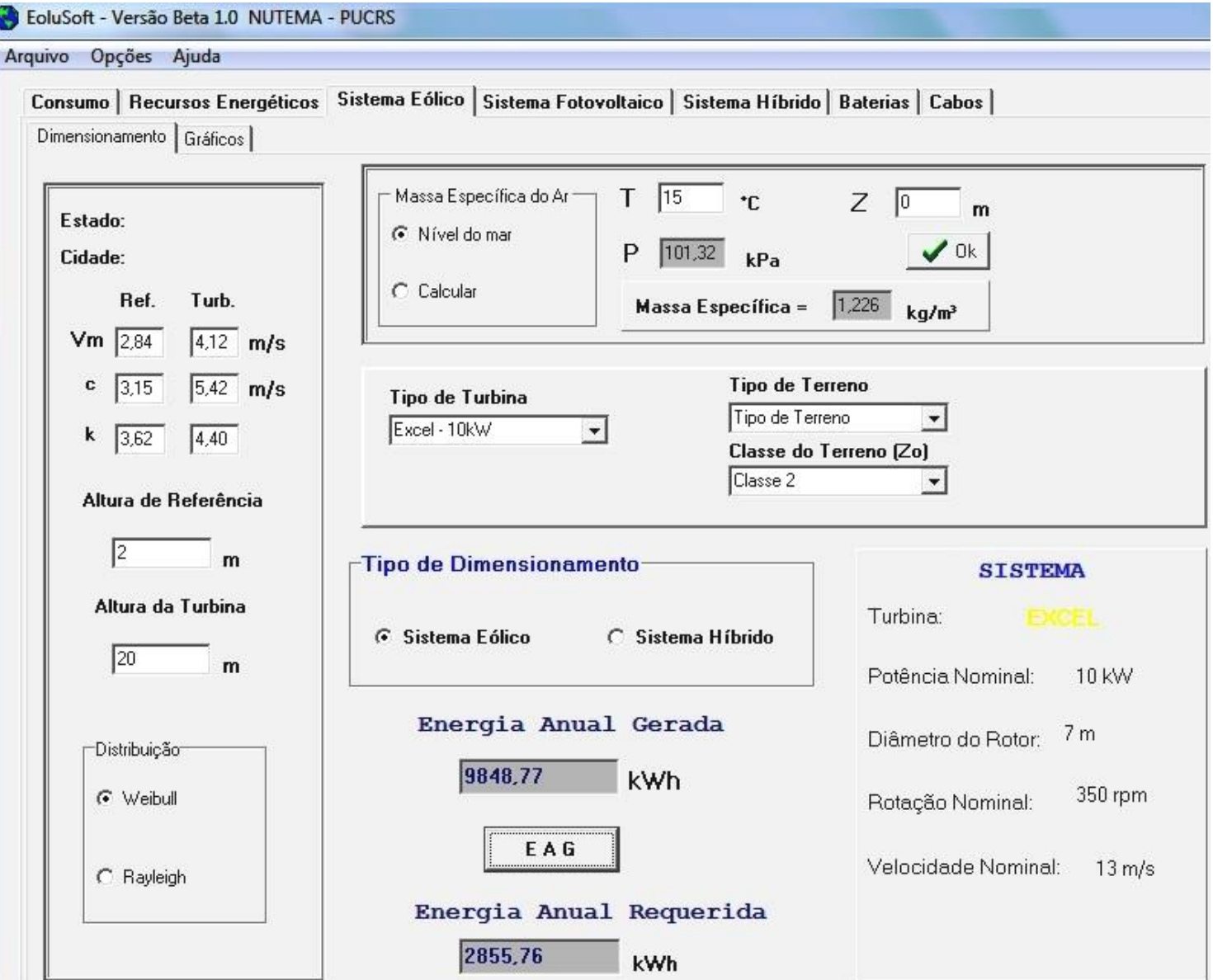

Figura 7: Dimensionamento da quantidade de energia gerada pela turbina eólica no Perímetro Irrigado Baixo-Acaraú, CE

A ANEEL (2014) acrescenta ainda que o sistema de compensação de energia elétrica é um sistema no qual a energia ativa injetada por unidade consumidora com microgeração distribuída ou minigeração distribuída é cedida, por meio de empréstimo gratuito, à distribuidora local e posteriormente compensada com o consumo de energia elétrica ativa dessa mesma unidade consumidora ou de outra unidade consumidora de mesma titularidade da unidade consumidora onde os créditos foram gerados.

Sobral, (2009a) em seu trabalho sobre a avaliação do potencial eólico para geração de energia em Nossa Senhora da Glória-SE. As simulações apontaram também uma capacidade de bombeamento com uma única bomba de água de 500 W ligada ao sistema eólico de referência um total de 2.021.760 litros de água bombeada por ano.

O mesmo critério de área utilizado na geração de energia elétrica pode ser aplicado para o volume de água a ser bombeado, sendo a capacidade de bombeamento para o perímetro irrigado na área do produtor rural utilizando o sistema de geração de energia elétrica por meio 
do aerogerador usando a bomba de $5 \mathrm{cv}$ e vazão de $10.800 \mathrm{l} \mathrm{h}^{-1}$, em que a sistema funcionando 4 horas por dia bombeará um volume de 43.200 litros por dia.

De acordo com Ramos e Seidler (2011) no seu trabalho com energia eólica para aproveitamento em pequenos empreendimentos no estado do Rio Grande do Sul, para suprir as necessidades de pequenas propriedades com um baixo custo de manutenção e de uma forma ecologicamente sustentável. Foi constatado que a velocidade média dos ventos foi de $2,5 \mathrm{~m} \mathrm{~s}$

${ }^{1}$, que já permitem a utilização de geradores de pequeno porte, suprindo a necessidade de energia em regiões remotas ou até mesmo auxiliando nos custos dos gastos com energia no processo produtivo.

\section{Conclusão}

A simulação do sistema eólico como alternativa energética para atender as necessidades de alimentação elétrica rural no perímetro irrigado com as condições de velocidade de vento local é capaz de fornecer o abastecimento de água, principalmente no que diz respeito ao bombeamento de água para a irrigação, representando uma economia de energia considerada no processo de produção agrícola. 


\section{Referências}

AGENCIA NACIONAL DE ÁGUAS (ANA). Projeto de Gerenciamento Integrado das Atividades na Bacia do São Francisco ANA/GEF/PNUMA/OEA. Subprojeto 4.5C Plano Decenal de Recursos Hídricos da Bacia Hidrográfica do Rio São Francisco PBHSF (2004-2013). Estudo Técnico de Apoio ao PBHSF - $\mathbf{N}^{\circ} 12$ Agricultura Irrigada. Brasília, Distrito Federal; 2004.

ARAUJO, A. C. D; NETO, J. D; LIRA, V. M; LIMA, V. L. A. Avaliação dos custos de energia elétrica no contexto operação e manutenção dos projetos públicos de irrigação. Enciclopédia Biosfera, Centro Científico Conhecer - Goiânia, vol.7, N.12; 2011.

AGÊNCIA NACIONAL DE ENERGIA ELÉTRICA (ANEEL). Disponível em: <http:॥www.inmet.gov.br > Acesso em 12 fev. 2014.

BORGES NETO, M. R. Ferramenta Computacional Aplicada ao Planejamento de Abastecimento de Eletricidade no Meio Rural. 2007. Dissertação de Mestrado em Engenharia Elétrica. Universidade Federal do Ceará- Fortaleza-CE.

CUSTÓDIO, R. S. Energia eólica para produção de energia elétrica, Eletrobrás, Rio de Janeiro, 2009. 280p.

FIDELIS, N. S.; ROSA, L. P.; ARAÚJO, M. R. The utilization of wind energy in Brasilian eletric sector's expansion", Renewable and Sustainable Energy Rewiews, vol 9, jun. pg 289-309. 2005

INSTITUTO NACIONAL DE METEOROLOGIA (INMET). Disponível em: <http: Iwww.inmet.gov.br > Acesso em 23 fev 2014.

LARA. M. Perímetros de irrigação pública respondem por menos de $10 \%$ da área irrigada no $\quad$ Brasil. $2010 . \quad 201$ em <www.canalrural.com.br/canalrural/jsp/default.jsp?uf=1\&loc>, Acesso em 20/08/2013.

LACERDA, N. B.; OLIVEIRA, T. S. Agricultura irrigada e a qualidade de vida dos agricultores em perímetros do Estado do Ceará, Brasil. Revista Ciência Agronômica, ISSN 0045-6888. v. 38, n.2, p.216-223, 2007.

MEDEIROS, S. S.; SOARES, A. A.; RAMOS, M. M.; MANTOVANI, E. C. SOUZA, J. A. A. Avaliação da eficiência do uso da energia elétrica no Perímetro Irrigado de Pirapora, MG, Revista Brasileira de Engenharia Agrícola e Ambiental, v.7, p.394-398, 2003.

NOGUEIRA, C. U. Utilização de sistemas solar e eólica no bombeamento de água para uso na irrigação. Dissertação de mestrado - Universidade Federal de Santa Maria. Centro de Tecnologia. Programa de Pós-Graduação em Engenharia de Produção. RS. 2009. 100 f.; il.

OLIVEIRA, F. A.; AlBUQUERQUE, J. A.; GADELHA, W. S. Potencialidades dos Perímetros Irrigados do DNOCS. Fortaleza, escritório técnico de estudos econômicos do Nordeste, 2012, 199 p. 
RAMOS, F. G.; SEIDLER, N. Estudo da energia eólica para aproveitamento em pequenos empreendimentos. Vivências: Revista Eletrônica de Extensão da URI. Vol.7, N.13: p.108-127, Outubro/2011.

SOBRAL, F. S. B. Avaliação do potencial eólico para geração de energia na zona rural do Estado de Sergipe. Dissertação (Mestrado em Desenvolvimento e Meio Ambiente) Universidade Federal de Sergipe, São Cristóvão, 2009. 168 f. : il.

SOBRAL, F. S. B. \& FACCIOLI, G. G. Avaliação do potencial eólico para geração de energia em nossa Senhora da Glória-SE. Revista Scientia Plena, Vol. 5, Num. 6, 2009

TURCO, J. E. P., RIZZATTI, G. S., PAVANI, L. C. Custo de energia elétrica em cultura do feijoeiro irrigado por pivô central, afetado pelo manejo da irrigação e sistemas de cultivo. Revista Brasileira de Engenharia Agrícola, v.29, p.311-320, 2009. 